Correspondence: A.M. Jones, Manchester Adult Cystic Fibrosis Centre, Wythenshawe Hospital, Southmoor Road, Manchester M23 9LT, UK. E-mail: andrew.jones@uhsm.nhs.uk

Statement of Interest: None declared.

\section{REFERENCES}

1 Jones AM, Govan JR, Doherty CJ, et al. Spread of a multiresistant strain of Pseudomonas aeruginosa in an adult cystic fibrosis clinic. Lancet 2001; 358: 557-558.

2 Cheng K, Smyth RL, Govan JR, et al. Spread of $\beta$-lactam-resistant Pseudomonas aeruginosa in a cystic fibrosis clinic. Lancet 1996; 348: 639-642.

3 Armstrong DS, Nixon GM, Carzino R, et al. Detection of a widespread clone of Pseudomonas aeruginosa in a pediatric cystic fibrosis clinic. Am J Respir Crit Care Med 2002; 166: 983-987.

4 Aaron SD, Vandemheen KL, Ramotar K, et al. Infection with transmissible strains of Pseudomonas aeruginosa and clinical outcomes in adults with cystic fibrosis. JAMA 2010; 304: 2145-2153.
5 Emerson J, Rosenfeld M, McNamara S, et al. Pseudomonas aeruginosa and other predictors of mortality and morbidity in young children with cystic fibrosis. Pediatr Pulmonol 2002; 34: 91-100.

6 Jones AM. Eradication therapy for early Pseudomonas aeruginosa infection in CF: many questions still unanswered. Eur Respir J 2005; 26: 373-375.

7 UK Cystic Fibrosis Trust Antibiotic Working Group. Antibiotic Treatment for Cystic Fibrosis. 3rd Edn. Bromley, Cystic Fibrosis Trust, 2009.

8 Lee TWR, Brownlee KG, Denton M, et al. Reduction in prevalence of chronic Pseudomonas aeruginosa infection at a regional paediatric cystic fibrosis center. Pediatr Pulmonol 2004; 37: 104-110.

9 Jones AM, Dodd ME, Govan JRW, et al. Prospective surveillance for Pseudomonas aeruginosa cross-infection at a cystic fibrosis center. Am J Respir Crit Care Med 2005; 171: 257-260.

10 Macdonald D, Cuthbertson L, Doherty C, et al. Early Pseudomonas aeruginosa infection in individuals with cystic fibrosis: is susceptibility testing justified? J Antimicrob Chemother 2010; 65: 2373-2375.

\title{
Diagnosis of respiratory viral infections in cystic fibrosis by PCR using sputum samples
}

\section{To the Editors:}

Recent epidemics of virulent respiratory viruses, such as H1N1 influenza and severe acute respiratory syndrome coronavirus (SARS-CoV), have highlighted the clinical importance of methods for the rapid and accurate detection of respiratory virus infection $[1,2]$. A diagnosis of a respiratory viral infection may have implications for infection control measures and treatment of patients [3]. Molecular-based techniques offer a more rapid and sensitive method for diagnosis of respiratory viral infection than viral culture or serology [4]. PCR-based methods can be applied to nasal and/or throat swab samples for the rapid detection of common respiratory viruses [5]. As the majority of adults with cystic fibrosis (CF) produce sputum during infective exacerbations, we investigated whether sputum is a suitable medium for the diagnosis of respiratory viral infections in patients with $\mathrm{CF}$ using a PCR method, by comparing results of PCR tests from paired sputum and nasal swab samples collected from patients with symptoms of a viral respiratory illness.

We prospectively collected paired nasal swab and sputum samples from adult patients with CF who presented with symptoms of a respiratory viral illness during the period December 2008 to June 2009. Flocked nasal swab samples were transported to the laboratory in viral transport medium (Microtest ${ }^{\mathrm{TM}} \mathrm{M}^{\mathrm{R}} \mathrm{RT}_{\text {}}$; Remel, Lenexa, KS, USA).

The samples were investigated using an in-house PCR method to detect common respiratory viruses (rhinovirus, influenza A, influenza B, parainfluenza types 1-3, adenovirus, respiratory syncytial virus (RSV) and metapneumovirus).
Permission for the study was granted by the local medical ethics committee. All patients gave verbal informed consent for participation in the study.

Group results were compared by a McNemar test using the SPSS statistical package, version 15 (SPSS Inc., Chicago, IL, USA).

Paired samples were analysed from 53 patients. 25 (47.2\%) patients had positive results with 26 viruses detected: 13 rhinovirus, three influenza A, three influenza B, three parainfluenza type 3, two adenovirus, one RSV and one metapneumovirus. Of the 25 positive results, all (100\%) sputum samples were positive, whilst $17(68 \%)$ nasal swab samples were positive $(p=0.008)$. One patient had both positive nasal and sputum samples for rhinovirus, but the sputum sample was also positive for adenovirus.

The importance of rapid, specific and sensitive tests for respiratory viral infections has been highlighted by recent epidemics of virulent respiratory viruses, such as $\mathrm{H} 1 \mathrm{~N} 1$ pandemic influenza [1] and SARS-CoV [2]. This study has shown that sputum, which is a readily available sample, is a suitable specimen for analysis by PCR for the rapid diagnosis of common respiratory viral infections. A previous study also reported success in detection of virus infection using a PCR technique with sputum samples for patients with $\mathrm{CF}$, but did not compare yield with traditional nasal samples [6]. In our clinical practice, the sensitivity of PCR is greater using sputum than nasal swab samples.

Tissue culture and serology were previously used as the standard tools for screening for viral infections, but have 
disadvantages compared with modern molecular methods, including a lower sensitivity and greater delay before the result is available [7, 8]. The prompt and accurate detection of a respiratory virus infection in patients with underlying lung disease is important for a number of reasons. Anti-viral medications are sometimes indicated for patients with a suspected or confirmed respiratory viral infection, particularly RSV or influenza [9]. Some respiratory viral infections are associated with increased morbidity and mortality in patients with chronic lung disease [10]. Confirmation of a respiratory viral infection may therefore prompt early institution of close monitoring and supportive measures, or commencement of preemptive antibiotic therapy to prevent clinical deterioration from an accompanying bacterial exacerbation, particularly for those patients with known chronic bacterial infection. In addition, infection control measures may require prompt diagnosis of a respiratory viral infection [3]. For example, since this study ended, a case of pandemic H1N1 influenza was positive by sputum PCR but negative by nasal swab PCR. In some cases, the identification of a respiratory virus by PCR was not confirmed from a nasal swab specimen but was confirmed from an accompanying sputum sample. As many adults with CF and other chronic lung diseases produce sputum during infective exacerbations, this may be an easily available and acceptable specimen to obtain from patients for screening for viral infection, with greater sensitivity than nasal swab samples.

\footnotetext{
A.M. Jones*, , W. Flight*, B. Isalska , M. Cullen , K. Mutton ${ }^{+}$, A. Bowling* , D. Riley*, K. Webb*,\# and R. Bright-Thomas*,\# *Manchester Adult Cystic Fibrosis Centre, "Medical Microbiology, University Hospitals South Manchester NHS Trust, "Respiratory Research Group, Faculty of Medical and Human Sciences, The University of Manchester, Manchester Academic Health Centre, and ${ }^{+}$Dept of Virology, Manchester Royal Infirmary, Manchester, UK.
}

Correspondence: A.M. Jones, Manchester Adult Cystic Fibrosis Centre, University Hospitals South Manchester NHS
Trust, Southmoor Road, Manchester M23 9LT, UK. E-mail: andrew.jones@UHSM.nhs.uk

Statement of Interest: None declared.

\section{REFERENCES}

1 Perez-Padilla R, de la Rosa-Zamboni D, Ponce de Leon S, et al. Pneumonia and respiratory failure from swine-origin influenza A (H1N1) in Mexico. N Engl J Med 2009; 361: 680-689.

2 Booth C, Matukas L, Tomlinson G, et al. Clinical features and short-term outcomes of 144 patients with SARS in the greater Toronto area. JAMA 2003; 289: 2801-2809.

3 British Infection Society, British Thoracic Society, Health Protection Agency. Pandemic flu: clinical management of patients with an influenza-like illness during an influenza pandemic. Provisional guidelines from the British Infection Society, British Thoracic Society, and Health Protection Agency in collaboration with the Department of Health. Thorax 2007; 62: Suppl. 1, 1-46.

4 Johnston S, Sanderson G, Pattemore P, et al. Use of polymerase chain reaction for diagnosis of picornavirus infection in subjects with and without respiratory symptoms. J Clin Microbiol 1993; 31: 111-117.

5 Collinson J, Nicholson K, Cancio E, et al. Effects of upper respiratory tract infections in patients with cystic fibrosis. Thorax 1996; 51: 1115-1122.

6 Punch G, Syrmis MW, Rose BR, et al. Method for detection of respiratory viruses in the sputa of patients with cystic fibrosis. Eur J Clin Microbiol Infect Dis 2005; 24: 54-57.

7 Wat D, Doull I. Respiratory virus infections in cystic fibrosis. Paediatr Respir Rev 2003; 4: 172-177.

8 Clifton IJ, Kastelik JA, Peckham DG, et al. Ten years of viral and non-bacterial serology in adults with cystic fibrosis. Epidemiol Infect 2008; 136: 128-134.

9 Jefferson T, Demicheli V, Rivetti D, et al. Antivirals for influenza in healthy adults: systematic review. Lancet 2006; 367: 303-313.

10 Bhat $\mathrm{N}$, Wright $\mathrm{J}$, Broder $\mathrm{K}$, et al. Influenza-associated deaths among children in the United States, 2003-2004. N Engl J Med 2005; 353: 2559-2567.

\section{Exacerbations of idiopathic pulmonary fibrosis treated with corticosteroids and cyclophosphamide pulses}

\section{To the Editors:}

Acute exacerbations (AEs) are now recognised as a frequent and severe complication of idiopathic pulmonary fibrosis (IPF). In a large series, 1- and 3-yr incidences were $14.2 \%$ and $20.7 \%$, respectively [1]. New diagnostic criteria were published in 2007 [2]. The pathogenesis of these episodes remains unknown, although invasive procedures have been described as possible triggers. Prognosis is poor, with a short-term mortality rate of $45-85 \%$. There is no consensus regarding treatment, as no published study has compared the efficiency of different treatment regimens, and treatment often differs between patients within a given study [1-4]. Since 2005, exacerbations of IPF identified in our referral centre (Centre Hospitalier Régional de Lille, Lille, France) have been treated with pulses of methylprednisolone followed by pulses of cyclophosphamide [5]. The main goal of the present retrospective study was to evaluate the mortality of exacerbations of IPF treated with this regimen.

Following admission for aggravation of dyspnoea, a series of tests were run to determine diagnosis and functional impairment. When an exacerbation of IPF was diagnosed, patients were treated with a methylprednisolone pulse $(1,000 \mathrm{mg})$ at days 1-3 